\title{
Symposium addresses the challenges of an ageing population
}

In September, the Continental European division of the International Association for Dental Research (CED-IADR), together with the association's Scandinavian division (NOF), welcomed more than 500 participants from 47 countries all over the world to the 2021 hybrid CED-IADR/NOF Oral Health Research Congress in Brussels, Belgium. The event, held over two and a half days, offered a broad scientific programme consisting of state-of-the-art symposia, keynote lectures and presentations by researchers from Europe and beyond.

On the first day, GC Europe hosted a symposium focusing on the challenges of an ageing population with respect to cervical lesions. The symposium, chaired by Professor Avijit Banerjee (King's College London, UK), was opened by Professor Jo Frencken (Radboud University, Netherlands) with consensus recommendations for the primary and secondary prevention of root caries lesions and their operative management.

Being a founding father of atraumatic restorative treatment (ART), he emphasised its ease of application and effectiveness of its use in modern caries management. According to Professor Frencken, ART with high-viscosity glass ionomer cement has been proved to be a successful approach to managing root surface caries.

The next speaker was Professor Falk Schwendicke (Charité - Universitätsmedizin Berlin, Germany) who pointed out the importance of cost assessment of treatment. The prevalence of non-carious cervical lesions increases with age. The first focus should always be on prevention and nonrestorative treatment. However, when the treatment fails or symptoms arise, restorative treatment is unavoidable. In his clinical study on EQUIA Forte for Class V restorations, he demonstrated not only the good performance and advantages of glass hybrid restoratives but also their cost-effectiveness, being $20 \%$ less costly than composite over the threeyear follow-up period.

The series of lectures was closed by Dr Gerry McKenna (Queen's University Belfast, UK), who provided a broad overview on ways to optimise treatment for older adults. In addition to preventive care and preservation of natural teeth, he recommended that tooth replacement follows a functionally oriented approach. At the end of the day, Professor Banerjee moderated a Q\&A session during which the participants could resume the discussion on this trending topic.

Having attracted over 100 participants online and on-site, the symposium was considered to be a great success.

For further information contact GC UK on 01908 218999, email info.uk@gc.dental or visit www.gceurope.com.

\section{Exceptional instruments for an exceptional time}

In an exceptional time for dentistry, endodontists need exceptional instruments.

To deliver treatment safely and efficiently, COLTENE is the number-one choice for specialists who always want successful outcomes.

Its HyFlex EDM file system has strength, flexibility and can be used with the CanalPro Jeni, an all-in-one endomotor and apex locator and game changing digital revolution in canal preparation, allowing autonomous navigation in the endo canal.

Whether you're new to endodontics or have many years under your belt, you will meet your patients' needs when you choose COLTENE. Browse the range on the website and start your journey to upgraded dentistry.

For more on COLTENE, visit www. coltene.com,email info.uk@coltene.com or call 08002545115.

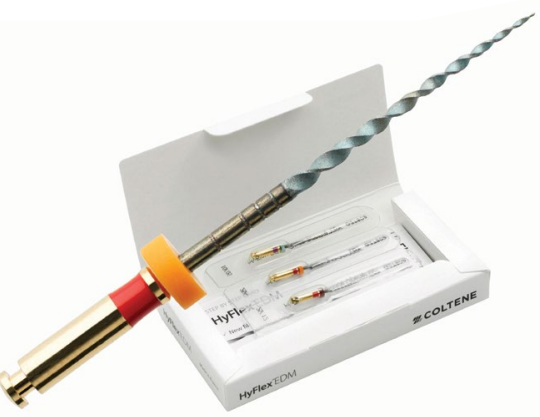

\section{Extra protection against the 'twindemic'}
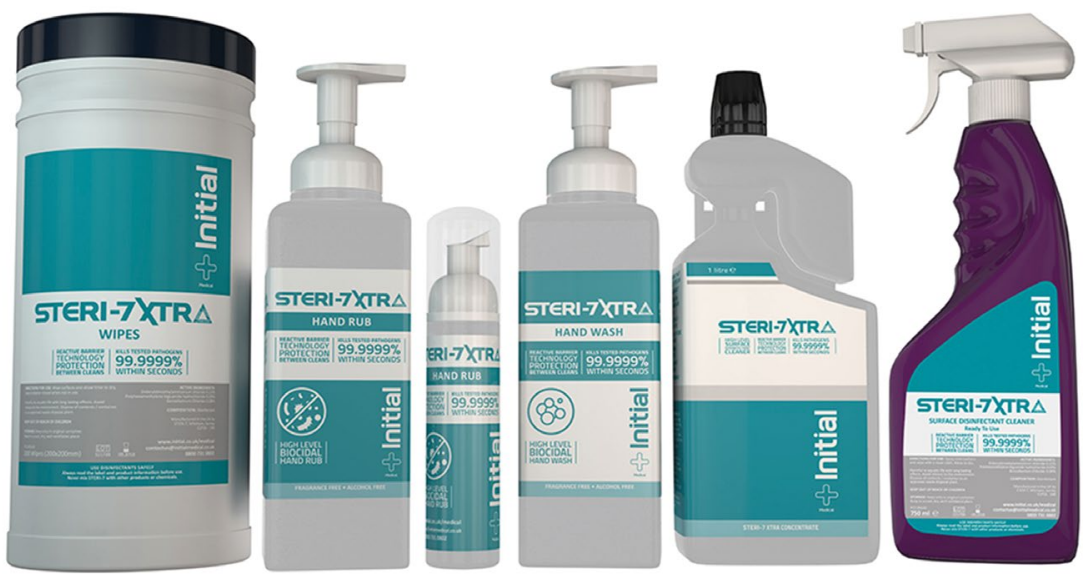

Experts are warning that we could soon be experiencing a 'twindemic' as coronavirus and influenza co-circulate.

Help defend your practice against this threat with the high-quality Steri-7 Xtra range of disinfectants from Initial Medical.

Effectively able to eliminate $99.99 \%$ of all pathogens including both influenza and coronavirus [tested against feline coronavirus, a surrogate virus for coronavirus], these solutions are safe to use throughout your practice, are delicate on equipment and provide lasting protection. Formulated with Reactive Barrier Technology, the whole range prevents the recolonisation of pathogens on treated surfaces for up to 72 hours as long as the product isn't wiped away after application.

Boost your defences and keep your practice safe by contacting Initial Medical to find out more.

For further information visit www. initial.co.uk/medical or Tel: 08708504045 . 